EMBRYARIDDLE
Aeronautical University

SCHOLARLY COMMONS
International Journal of Aviation, Aeronautics, and Aerospace

\title{
Mini Unmanned Aerial Systems (UAV) - A Review of the Parameters for Classification of a Mini UAV.
}

\author{
Ramesh PS \\ Lovely Professional University, psramesh1026@gmail.com \\ Muruga Lal Jeyan \\ Lovely professional university, jvmlal@ymail.com
}

Follow this and additional works at: https://commons.erau.edu/ijaaa

Part of the Aeronautical Vehicles Commons

\section{Scholarly Commons Citation}

PS, R., \& Jeyan, M. L. (2020). Mini Unmanned Aerial Systems (UAV) - A Review of the Parameters for Classification of a Mini UAV.. International Journal of Aviation, Aeronautics, and Aerospace, 7(3). https://doi.org/10.15394/ijaaa.2020.1503

This Literature Review is brought to you for free and open access by the Journals at Scholarly Commons. It has been accepted for inclusion in International Journal of Aviation, Aeronautics, and Aerospace by an authorized administrator of Scholarly Commons. For more information, please contact commons@erau.edu. 
The advent of Unmanned Aerial Vehicle (UAV) has redefined the battle space due to the ability to perform tasks which are categorised as dull, dirty, and dangerous. UAVs re-designated as Unmanned Aerial Systems (UAS) are now being developed to provide cost effective efficient solutions for specific applications, both in the spectrum of military and civilian usage. US Office of the Secretary of Defense (2013) describes UAS as a "system whose components include the necessary equipment, network, and personnel to control an unmanned aircraft." In an earlier paper, US Office of the Secretary of Defense (2005) specifies UAV as the airborne element of the UAS and defines UAV as "A powered, aerial vehicle that does not carry a human operator, uses aerodynamic forces to provide vehicle lift, can fly autonomously or be piloted remotely, can be expendable or recoverable, and can carry a lethal or non-lethal payload." John (2010) provided an excellent historical perspective about the evolution of the UAVs. Although the UAVs were in existence in some form or the other, since the early twentieth century, Operation Desert Storm in 1991 witnessed the coming of age of the UAVs in the true sense. Today we have UAVs which can travel across continents to the ones which can fly in our drawing rooms, the end use dictating the design and technology associated with these flying machines. Austin (2011) defined Mini UAV, but with adequate scope for interpretation. As per the author, "Mini UAV relates to UAV of below a certain mass, probably below $20 \mathrm{~kg}$, but not as small as the MAV (Micro Air Vehicles), capable of being hand-launched and operating at ranges of up to about $30 \mathrm{~km}$." Over the years, various scholars continue to persist with similar vague definition of Mini UAVs and this has denied a common identity for Mini UAV across the scientific world and amongst manufacturers.

The review is organized in the next sections as follows: 'Classification of Mini UAV' section examines the criteria for classifying UAVs in various published literature. The 'Factors for Classification of UAV' discusses various parameters for classifying UAVs. The next section analyses the work of various researchers to identify the criteria used for categorising the Mini UAV. In addition, the data of the fixed and rotary wing in production Mini UAVs have also been studied in this section. This is followed by discussion and analysis of the observations from the preceding sections. The contradictions and the necessity to define parameters have been explained. Finally, section 6 concludes the paper.

\section{Classification of UAV}

Most studies (Austin, 2011; Anderson, 2013; Cai et al., 2014; Gupta et al., 2013; Hassanalian et al. 2017; Weibel, 2014) classify the UAVs as High Altitude Long Endurance (HALE) UAV, Medium Altitude Long Endurance (MALE) UAV, Tactical UAV, Small UAV and Mini and Micro UAVs. Parameters used for classification includes endurance, range, altitude and weight with minor variations. There is a certain amount of uniformity amongst the authors in classification of bigger UAVS like RQ-4 Global Hawk and MQ- 
1 Predator. Even for the micro or miniature UAVs like the Black Widow UAV, classification is more or less standard. However, the lines are blurred when it comes to distinguishing between small, mini or micro UAVs. Small UAV covers a wide spectrum and could be either a tactical UAV or a mini UAV or even micro UAV. Figure1 gives out a spectrum of the current UAV.

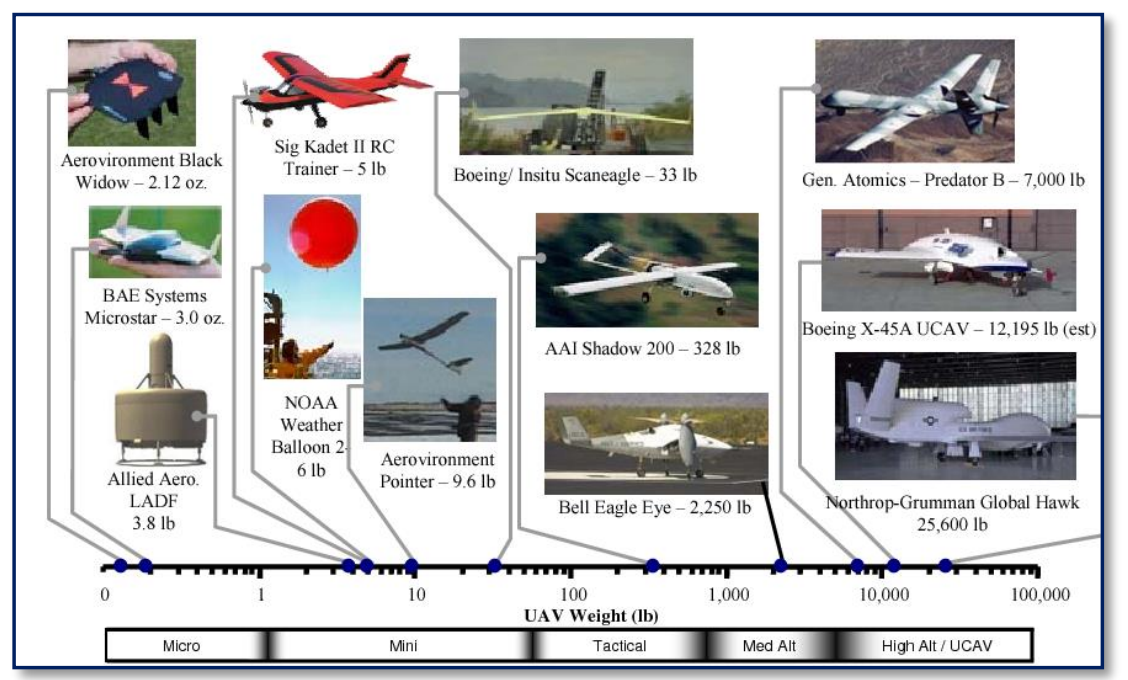

Figure 1. Spectrum of Current UAVs Weibel (2014).

Villa et al. (2016) aptly brought out that "Several platform classifications have already been proposed, however, the nomenclature adopted for civil and scientific use has generally followed the existing military descriptions of size, flight endurance and capabilities." What constitutes the capabilities is yet again left to interpretation. Weibel (2014) classified the UAVs as HALE, Male, mini and micro. HALE UAV flies at altitude above $15000 \mathrm{~m}$ with more than 24 hours endurance and can carry out extremely long-range (trans-global) reconnaissance. MALE UAV flies at an altitude of 5000-15000 $\mathrm{m}$ and has about 24 hours of endurance. Their roles are similar to the HALE systems but generally operate at somewhat shorter ranges, but still in excess of $500 \mathrm{~km}$ and from fixed bases. TUAV has ranges up to $300 \mathrm{~km}$ with 10 to 12 hours of endurance flying at altitudes beyond $3000 \mathrm{~m}$. However, Mini UAV does not have a clearly defined parameter, an aspect which will be dealt in greater detail in the paper. The MAV was originally defined as a UAV having a wing-span no greater than $150 \mathrm{~mm}$. The commercially popular Quadcopters and Hexacopters have limited military applications due to the limitations of endurance and are at best grouped with the MAV or the miniature UAVs. In some cases, the UCAV (Unmanned Combat Air Vehicle) NAV (Nano Air Vehicles), RPH (Remotely Piloted Helicopter) or VTUAV is also included in the classification. When it comes to the dimensions, capabilities and employment the classification is yet again diverse. Across the world, UAV are employed by army, navy and the air force, each having 
specific parameters for tactical deployment which in turn dictates the classification. Similarly, UAVs used for civil applications follow a divergent set of parameters to classify Mini UAVs. Figure 2 illustrates one of the classifications of UAV.

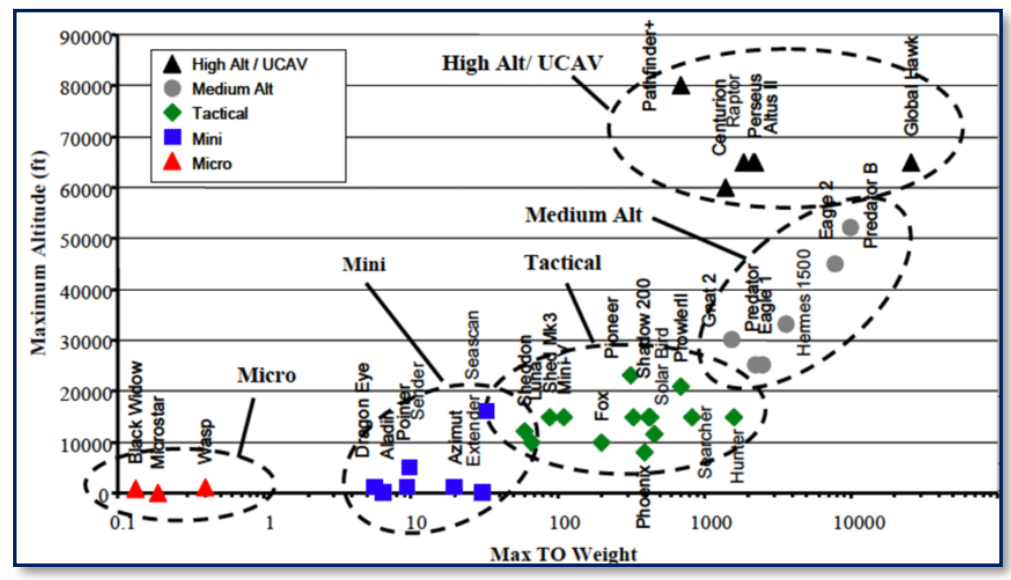

Figure 2. Classification of UAV, Weibel (2014).

\section{Factors for Classification of Mini UAV}

The family of UAV can be classified in many ways. In order to have a common understanding of what defines Mini UAV, it is imperative to define the parameters for classification of the family of UAVs. In an exhaustive study by Maziar A. et al. (2013), various norms have been used for classification of UAVs. Based on performance characteristics, weight endurance, range, maximum, altitude wing loading, engine type, and power/thrust loading have been used for classification. Purely from the exploitation or the end use, the aerials vehicles can be classified based on the under-mentioned factors.

\section{Operating Altitude}

The altitude above mean sea level altitude up to which the UAV can fly will determine the operating altitude. Density being a factor in generating the desired lift, the capabilities to operate under specific terrain conditions in terms of altitude ceiling is an important element in deciding the class of the UAV. Mini UAVs required to take off from higher altitudes should have higher operating altitude. Operating altitude is given in terms of mean sea level reference, while the AGL (above ground level) flying ability is a factor of the payload and the data link. Higher AGL flying ability in case of military applications would also result in requirement to operate at higher ceiling. In case of civilian applications, AGL will relatively less restricting factor.

\section{Endurance}

Endurance is the airborne time of the flying machine. Endurance relates to the type and performance of the power plant. Quantum of fuel and fuel consumption rate along with the environmental conditions will determine the endurance in case of gasoline operated UAVs and the life of battery for the 
electrically operated ones. The type and design of the UAV is an important factor that dictates the endurance. Military applications would require relatively higher endurance as compared to civilian applications because of higher loiter time and longer ranges of operations.

\section{Operating Range}

Operating range is the radial distance from the ground control station. The range is a factor of the data link as well as the endurance of the aerial vehicle. The terrain, particularly in mountains, may impose restrictions on the operating range due to line of sight considerations for the data link between the UAV and the Ground Control Station (GCS). For military applications, the ranges required will be invariably higher because of the stand-off distances involved. In cases of civilian applications, take-off and landing from close to the target is unlikely to be a restricting factor.

\section{Max Take-Off Weight (MTOW)}

MTOW is also referred to as all up weight. Mini UAV is man portable systems, designed to be handled by a two men team within a mobile battle group in case of tactical operations. Apart from the air vehicle, the weight of the GCS and all components of the data link and other accessories will also have to be factored from the portability point of view. This is of particular importance while operating in terrain where vehicular access is not available.

\section{Payload}

In case of the higher class of UAV like the HALE and MALE, payload is a significant factor. UAVs in these classes may carry multiple payload or interchangeable payloads like surveillance cameras, synthetic aperture radar, missiles etc. However, in case of smaller machines, payload would by and large remain the same, specific to the design and the intended application. Drag in case of the smaller UAVs is magnified and hence an important design factor for payload selection and design. The shape, size and location of the payload will therefore be configured to keep the drag at the lowest level.

\section{Size}

Mini UAV being man portable systems, all subsystems, the UAV, GCS data link and other accessories will have to be carried by a two men team. It will be preferable to design the subsystems which can be easily and quickly dismantled and assembled. The design has to pay sufficient attention to ergonomics of the system as a whole in order to facilitate ease of carriage.

\section{Categorising Mini UAV}

Since unmanned systems were primarily developed for military purpose, the country specific tactical parameters influenced the classification. Consequently, there is no across the board unanimity amongst authors and researchers regarding the classification of the UAV and the parameters which defines the classification.

Cai et al. (2010) referred to Mini UAVs as miniature and clubs it with aerial vehicles (MAVs) with wingspan or rotorspan less than $15 \mathrm{~cm}$. Instead of MTOW, payload attributed with few tens of kilograms has been used to 
describe a Mini UAV. Various in production UAVs have been analysed. However, there is no uniformity when it comes to categorising the class of Mini UAV or Mini UAS. Standardisations of critical parameters that define tactical employment like range, endurance, operating altitude, all up weight, size and payload are not clearly spelt out. The variations could be due to the country specific tactical specifications supplemented by the variations in air, land and naval forces operating environment. Similar argument holds true for civil applications as well.

Villa et al. (2016) grouped the UAV into five categories, following the U.S. Department of Defense classification. However, classification parameters for a Mini UAV do not find a mention in the study.

Marin et al. (2014) classified UAV based on size, weight, endurance, range and flying altitude. The UAVs are classified as Micro, Mini, Close range, Short range, Medium range, Medium range endurance, Low altitude deep penetration, Low altitude long endurance, Medium altitude long endurance (MALE). Mini UAV as categorised with weight category of 25 to $150 \mathrm{~kg}$, range less than 10 kilometers, flight altitude of 150 to 300 meters and endurance of less than two hours.

Gupta et al. (2013) bracketed Mini UAV with weight category, in this case ranging from 2 to $20 \mathrm{~kg}$, with flying altitude up to 3000 feet above ground level and range up to 25 kilometers. Endurance specified defies the norms and is given in terms of days, i.e. 2 days. Despite specifying the parameters, description of Mini UAV follows Austin (2011) with ranges up to $30 \mathrm{~km}$.

Hazim et al. (2019) provided a comprehensive study on the civil applications of UAV but the UAV is simply classified as Low Altitude Platform (LAP) and High Altitude Platform (HAP). Even the parameters assigned for the LAP are vague - Endurance of few hours, Altitude less than 5 Km, Range less than $200 \mathrm{Km}$ and Weight of 'Tens of kgs.'

In a recent study, Hartanto et al. (2019) explained that there is no one standard on the UAV classification. Two factors are used for classification i.e. US DoD classification norms and that of Information Technology for Assistance, Cooperation and Action (ITHACA). While the former uses five categories the lattes divides the UAV into only three categories.

In a study by Wang et al. (2013) Mini UAVs are described on the basis of wingspan between 100 to $300 \mathrm{~cm}$ and weight often less than 50 kilograms. Micro-UAV, as per the authors, has 15 to $100 \mathrm{~cm}$ 's long wingspan and weighs less than one kilogram. The study is silent on other parameters like range, endurance and operating altitude.

In an older study, Weed (2002) gave an excellent account of the genesis of the mini UAVs, the strengths and limitations with respect to military applications. He analyses the reasons for the larger Shadow 200 UAV to be accepted to meet brigade level requirements. Various mini UAVs like Pointer, Scout, Exodrone, and Cypher have been compared in the study. However, despite the variance, parameters that would define a mini UAV have 
not been spelt out and the inconsistencies in analysis have not been ironed out with time.

Hsu (2013) gave a good account of various classes of Chinese UAV but does not lay down clear cut parameters for classification. Mini UAV is characterised by low altitude, short endurance (about an hour) and close range, specifications that are subject to interpretation. Mini UAVs have been defined as a UAV light and small enough to be carried and operated by one human operator in the study by Lee et al. (2015). The only specific parameter mentioned defining a mini UAV is a wing span up to 1 meter or more. Kamali et al. (2016) analysed the requirements of hardware in the loop simulation for a mini UAV. The study was based on Slybird mini UAV with a wing span of 2 $\mathrm{m}$ and an endurance of 1 hour. In an exhaustive report to the House of Commons UK, Louisa (2015) classifies UAV solely as per their weight, categorising Mini UAV as the ones in 2 to $20 \mathrm{~kg}$ class.

Rawat et al. (2014) constructed and tested helicopter weighing 12 pounds with an endurance of 30 minutes and a maximum payload of 15 pounds and categorised it as Mini UAV. Anderson et al. (2013) simply described a mini UAV as "low and slow" systems, which typically "weigh less than 20 kilograms, have flight times of a few hours, and have very limited ranges". In their study, Cai et al. (2014) attributed Size $<5 \mathrm{~m}$, Gross Take Off Weight (GTOW) $10 \mathrm{~kg}$, Altitude <1200 AGL, Range <25km, Endurance Up to $48 \mathrm{~h}$, to a miniature UAV, presumably a mini UAV. Interestingly, the paper makes no mention of mini UAV as such, the term small tactical UAV has been used instead. In their study, Aswini et al. (2018) took into account only two parameters, weight 2 to $20 \mathrm{~kg}$ and altitude 300 feet in the classification of Mini UAV. In a recent study, Abdelwahid et al. (2019) considered three factors, endurance on 1 hour, altitude 300 feet and range MTOW $7 \mathrm{Kg}$. Jun et al. (2017) considered UAV with MTOW of $1.2 \mathrm{~kg}$ and flying speed of $10 \mathrm{~m} / \mathrm{s}$ in their study of UAV -borne crop-growth monitoring system. The authors were silent on the remaining parameters. Jason et al. (2016) while evaluating flight-test of kinematic precise point positioning of small UAVs did not specify the parameters of the UAV. Kadir et al. (2015), in their survey of UAVs, used the NATO classifications and considers 2-20 Kg weight, altitude up to $3000 \mathrm{ft}$ AGL and range $25 \mathrm{Km}$. Hassanalian et al. (2017) provided an overview of various modes of classification. While examining parametersbased classification the authors considered weight 2 to $20 \mathrm{Kg}$ and range 20 to $40 \mathrm{Km}$. Other parameters were not mentioned. Table 1 provides a summary of assessment of the parameters by various researchers. 
PS and Jeyan: Parameters for Classification of a Mini UAV.

\begin{tabular}{|c|c|c|c|c|c|}
\hline Ref & Altitude & Endurance & $\begin{array}{l}\text { Range } \\
\mathrm{Km}\end{array}$ & MTOW Kg & Size \\
\hline Austin (2011) & - & - & About 30 & $\begin{array}{l}\text { Probably } \\
\text { below } 20\end{array}$ & - \\
\hline Cai et al (2014) & $\begin{array}{c}<100 \text { to } \\
<3500 \\
\text { AGL }\end{array}$ & $\begin{array}{l}20 \text { minutes to } \\
48 \text { hours }\end{array}$ & $<10$ to $<50$ & $1-25$ & $\begin{array}{l}\text { Small Micro } \\
\text { Mini clubbed. }\end{array}$ \\
\hline $\begin{array}{l}\text { Villa et al. } \\
\text { (2016) }\end{array}$ & & Five cat & ories but no s & ecifications & \\
\hline $\begin{array}{l}\text { Marin et al. } \\
\text { (2014) }\end{array}$ & $150-300 \mathrm{~m}$ & $<2$ hours & $<10$ & $2-150$ & $\begin{array}{l}\text { Classified under } \\
\text { tactical UAVs }\end{array}$ \\
\hline $\begin{array}{l}\text { Gupta et al. } \\
\text { (2013) }\end{array}$ & $\begin{array}{l}\text { Up to } 3000 \\
\text { feet }\end{array}$ & 2 days & 25 & $2-20$ & Micro Mini \\
\hline $\begin{array}{l}\text { Hazim et al. } \\
\text { (2019) }\end{array}$ & $<5 \mathrm{~km}$ & & 200 & $\begin{array}{l}\text { Tens of } \\
\text { Kgs }\end{array}$ & LAP/HAP \\
\hline $\begin{array}{l}\text { Hartanto et al. } \\
\text { (2019) }\end{array}$ & \multicolumn{5}{|c|}{ No one standard on the UAV classification } \\
\hline Weed (2002) & \multicolumn{5}{|c|}{ Five categories but no specifications } \\
\hline Hsu (2013) & \multicolumn{5}{|c|}{ No clear parameters } \\
\hline Lee et al. (2015) & - & - & - & - & $\begin{array}{l}\text { Wing Span } 1 \mathrm{~m} \\
\text { or more }\end{array}$ \\
\hline $\begin{array}{l}\text { Kamali et al. } \\
\text { (2016) }\end{array}$ & - & 1 hour & - & - & Wing span $2 \mathrm{~m}$ \\
\hline Louisa (2015) & & & & $2-20$ & \\
\hline $\begin{array}{l}\text { Wang et al. } \\
\text { (2013) }\end{array}$ & - & - & - & $<50$ & $\begin{array}{l}\text { Wing span } 100 \\
\text { to } 300 \mathrm{~cm}\end{array}$ \\
\hline
\end{tabular}




\begin{tabular}{|c|c|c|c|c|c|}
\hline $\begin{array}{l}\text { Rawat et al. } \\
\text { (2014) }\end{array}$ & & 30 minutes & & 5.5 & \\
\hline $\begin{array}{l}\text { Anderson et al. } \\
\text { (2013) }\end{array}$ & & Few hours & $\begin{array}{c}\text { Very } \\
\text { limited } \\
\text { ranges }\end{array}$ & $<20$ & \\
\hline Cai et al. (2014) & 1200 feet & 48 hours & $<25$ & 10 & Wing span $<5$ m \\
\hline Aswini (2018). & 300 feet & - & - & $2-20 \mathrm{Kg}$ & - \\
\hline $\begin{array}{l}\text { Abdelwahid et } \\
\text { al. (2019) }\end{array}$ & $300 \mathrm{~m}$ & 1 hour & & $7 \mathrm{Kg}$ & \\
\hline Jun et al. (2017) & & & & $1.2 \mathrm{Kg}$ & \\
\hline $\begin{array}{l}\text { Jason et al. } \\
\text { (2016) }\end{array}$ & \multicolumn{5}{|c|}{ Not mentioned } \\
\hline $\begin{array}{l}\text { Kadir et al. } \\
\text { (2015) }\end{array}$ & $\begin{array}{c}<3000 \mathrm{ft} \\
\mathrm{AGL}\end{array}$ & - & - & $2-20$ & 25 \\
\hline $\begin{array}{l}\text { Hassanalian et } \\
\text { al. (2017) }\end{array}$ & - & - & - & $2-20$ & $20-40$ \\
\hline
\end{tabular}

As evident from the above, there is a lack of unanimity amongst researchers in defining the specifications and consequent divergent views in the definition of Mini UAVs. It is therefore apparent that both the classification and the categorisation of Mini UAV are not consistent.

\section{Parameters Adopted by Manufactures for Fixed Wing Mini UAVs}

Divergence in adopting parameters for defining Mini UAV by various manufacturers is amply clear from Table 2 . Wing span reflects the size of the UAV and also influences the aerodynamic performance and other parameters. Hence wing span has been used as a benchmark for comparisons. The data further corroborate the lack of uniformity amongst various manufacturers in outlining the factors that categorise a Mini UAV. One of the most striking aspect, clearly evident from Table 2, is difference in defining Mini UAV by various manufactures. This could be due to topological factors and/or tactical considerations of the respective countries, or it could be even based on the manufacturer's understanding. Few manufacturers have not considered all parameters. 
PS and Jeyan: Parameters for Classification of a Mini UAV.

\begin{tabular}{|c|c|c|c|c|c|c|c|}
\hline \multicolumn{8}{|c|}{ Table 2 - Fixed Wing Mini UAV Parameters } \\
\hline & Name & $\begin{array}{c}\text { Manufacture } \\
\mathrm{r}\end{array}$ & $\begin{array}{l}\text { Wing } \\
\text { Span } \\
(\mathrm{m})\end{array}$ & Range & $\begin{array}{c}\text { Altitude } \\
(\mathrm{m}) \\
\text { AMSL }\end{array}$ & Endurance & $\begin{array}{c}\text { MTO } \\
\text { W } \\
(\mathrm{Kg})\end{array}$ \\
\hline 1 & $\begin{array}{l}\text { RQ-11B } \\
\text { Raven }\end{array}$ & $\begin{array}{l}\text { Aero } \\
\text { Vironment }\end{array}$ & 1.4 & 10 & 4419 & $\begin{array}{c}1 \mathrm{hr} 30 \\
\min \end{array}$ & 1.9 \\
\hline 2 & Puma LE & $\begin{array}{l}\text { Aero } \\
\text { Vironment }\end{array}$ & 4.6 & 20 & 3200 & $\begin{array}{c}2 \mathrm{hr} 30 \\
\min \end{array}$ & 11.8 \\
\hline 3 & $\begin{array}{l}\text { Rotla Mini } \\
\text { UAV }\end{array}$ & Rolta & 2.8 & 20 & 3500 & $4 \mathrm{hrs}$ & 10 \\
\hline 4 & $\begin{array}{l}\text { FQM-151A } \\
\text { Pointer }\end{array}$ & $\begin{array}{l}\text { Aero } \\
\text { Vironment }\end{array}$ & 2.7 & 5 & 300 & 1 & 4.3 \\
\hline 5 & Wasp & $\begin{array}{l}\text { Aero } \\
\text { Vironment }\end{array}$ & 1 & 5 & 3499 & 50 mins & 1.3 \\
\hline 6 & $\begin{array}{l}\text { Spy' } \\
\text { Ranger }\end{array}$ & $\begin{array}{l}\text { Thales } \\
\text { Group }\end{array}$ & 3.9 & 30 & 4500 & $\begin{array}{c}2 \mathrm{hr} 30 \\
\min \end{array}$ & 14 \\
\hline 7 & $\begin{array}{l}\text { Bird-Eye } \\
\text { 650D }\end{array}$ & $\begin{array}{l}\text { Israel } \\
\text { Aerospace } \\
\text { Industries }\end{array}$ & 4.0 & 150 & 4572 & $15 \mathrm{hrs}$ & 30 \\
\hline 8 & BirdEye 650 & $\begin{array}{l}\text { Israel } \\
\text { Aerospace } \\
\text { Industries }\end{array}$ & 3 & 20 & 457 & 4 & 11 \\
\hline 9 & $\begin{array}{l}\text { Mini } \\
\text { Panther }\end{array}$ & $\begin{array}{l}\text { Israel } \\
\text { Aerospace } \\
\text { Industries }\end{array}$ & 3.2 & 20 & 500 & $2 \mathrm{hrs}$ & 12 \\
\hline 10 & $\begin{array}{l}\text { ZALA 421- } \\
16 \mathrm{E}\end{array}$ & $\begin{array}{l}\text { ZALA Aero } \\
\text { company }\end{array}$ & 1.6 & 50 & 3600 & $7 \mathrm{hrs}$ & 18 \\
\hline 11 & Bayraktar & Kale-Baykar & 2.0 & 15 & 1000 & $80 \mathrm{~min}$ & 3.5 \\
\hline 12 & Fly Eye & WB Group & 3.6 & 30 & 4000 & 2.5 & 11 \\
\hline 13 & Guardian & $\begin{array}{l}\text { OM UAV } \\
\text { Systems }\end{array}$ & 1.98 & 7.1 & 3000 & $70 \mathrm{~min}$ & 2.4 \\
\hline 14 & $\begin{array}{l}\text { TEKEVER } \\
\text { AR3 }\end{array}$ & $\begin{array}{l}\text { Tekever } \\
\text { Autonomous } \\
\text { Systems }\end{array}$ & 3.2 & 120 & NA & $10 \mathrm{hrs}$ & 23 \\
\hline 15 & PD-1 & $\begin{array}{l}\text { Ukrspec } \\
\text { Systems }\end{array}$ & 4 & 100 & 3000 & 10 & 40 \\
\hline
\end{tabular}




\begin{tabular}{|c|c|c|c|c|c|c|c|}
\hline 16 & $\begin{array}{l}\text { LELEKA- } \\
100\end{array}$ & $\begin{array}{l}\text { Ukrspec } \\
\text { Systems }\end{array}$ & 1.9 & 45 & 1500 & 2.5 & 5.5 \\
\hline 17 & CYGNUS & $\begin{array}{l}\text { Asteria } \\
\text { Aerospace }\end{array}$ & 2 & 15 & 5000 & 90 mins & 4 \\
\hline 18 & Orbiter II & $\begin{array}{l}\text { Aeronautics } \\
\text { Defense } \\
\text { Systems }\end{array}$ & 3 & 50 & 5486 & 3 & 10.3 \\
\hline 19 & SpyLite & $\begin{array}{l}\text { BlueBird } \\
\text { Aero } \\
\text { Systems } \\
\end{array}$ & 2.7 & 50 & 1000 & 4 hours & 9.5 \\
\hline 20 & CSV 15 & TASUMA & 2.7 & 20 & NA & 2 hours & 7 \\
\hline 21 & Scan Eagle & Boeing & 3.1 & NA & 5000 & 22 hours & 18 \\
\hline 22 & RQ-15A & $\begin{array}{l}\text { DRS } \\
\text { Technologies }\end{array}$ & 2.1 & 75 & 2438 & $4 \mathrm{hrs}$ & 36 \\
\hline 23 & Stream C & Therod & 3.9 & 50 & 3000 & 6 & 6 \\
\hline 24 & BOREY 20 & UAVOS & 4.3 & 430 & 3500 & 5 & 20 \\
\hline 25 & $\begin{array}{l}\text { SITARIA } \\
\text { E }\end{array}$ & UAVOS & 5.16 & 60 & 6000 & 3 & 39 \\
\hline 26 & Albatross & $\begin{array}{l}\text { Applied } \\
\text { Aeronautics }\end{array}$ & 3 & 40 & NA & 4 & 10 \\
\hline 27 & ALADIN & $\begin{array}{l}\text { EMT } \\
\text { Penzberg }\end{array}$ & 0.146 & 15 & 4500 & 1 & 4 \\
\hline 28 & GLOBIHA & $\begin{array}{l}\text { Global- } \\
\text { Teknik }\end{array}$ & 1.5 & 15 & 458 & 1.5 & 3.1 \\
\hline
\end{tabular}

The wing span varies from $0.14 \mathrm{~m}$ to $8 \mathrm{~m}$ with an average of about $2.73 \mathrm{~m}$. The older version UAVs like Scout and Panther, though called as Mini UAVs, are essentially the modern day small tactical UAV. In most cases the wings are detachable and can be assembled quickly under field conditions. Therefore, UAVs of this size are man portable. The UAVs which are relatively larger like the AR3 TEKEVER or SpyLite are catapult launched. This arrangement may be perfectly fine in a plain terrain. In mountainous terrain, catapult launch will have serious ramifications because of the availability of the clear space for launch. Moreover, in difficult terrain like the mountains, carriage of the catapult launch system will have associated problems. 
Recovery of the aircraft is yet another issue in case of fixed wing UAVs, particularly the larger ones. Automatic Parachute and airbag recovery are common means adopted for the recovery which can cause serious problems in mountainous terrain. UAVs like the Mini Panther uses tilt rotor for the fixed wing aircraft thus enabling VTOL to overcome the problem of launch and recovery.

As per the data available from open sources, there is no uniformity in operating altitude. Few of the manufacturers gave specification in terms of above mean sea level altitude (AMSL) while others specified above ground level (AGL). Smaller UAV like RQ-11B Raven FQM-or 151A Pointer opted for AGL while the larger ones like Rotla or SpyLite chose AMSL as the primary data. AGL reflects the payload and data link capability and does not necessarily take into account the aerodynamic performance of the flying machine. AMSL is linked to the operating terrain and directly affects the aerodynamic performance of the aircraft. Hence the operating altitude for the aircraft must be specified in terms of AMSL. AGL should essentially be used for describing the capabilities of the payload like the camera.

Endurance is directly related to the engine or battery used for powering the UAV. Aerodynamic profile, speed of flight and density are other important factors which govern the endurance of the system. Endurance, as stated in Table 2, ranges from 50 minutes in case of Wasp to 22 hours for the ScanEagle covering a significantly wide spectrum. Endurance is connected to the type of application or the end use of the UAV. For example, in case of agriculture application, the UAV can be launched from in situ or from close proximity. However, for tactical employment, more often than not the UAV will have to be launched from a distance from the intended target area. Therefore, the distance traversed to reach the target area will be essentially dead mileage, yet would account for the endurance of the UAV.

The operating range is a factor of topographical conditions, the data link and endurance of the UAV therefore comparison becomes even more complex. UAVs having higher operating altitude will have an advantage of fewer restrictions of line of sight under while functioning in similar terrain. BOREY 20 top the list with $430 \mathrm{~km}$, while GSV-37 Breeze has the least range of $0.15 \mathrm{~km}$. As evident from Table 2, larger weight of the UAV does not necessarily translate to higher performance in other parameters. ScanEagle, despite having a MTOW of only $18 \mathrm{Kg}$, gives an endurance of 22 hours. On the other hand, Panther with an MTOW of $63.5 \mathrm{Kg}$ has an endurance of only 6 hours. Wasp UAV is the lightest at $1.3 \mathrm{~kg}$ and the CAMCOPTER S-100 at the other extreme has an MTOW of $200 \mathrm{Kg}$. Even the inter se comparison of the parameters exhibits inconsistencies in defining a mini UAV or UAV. While there might be some errors in the data obtained from various manufacturer's data the overall profile is not incongruous. For example, there is a marginal difference in the wing span between Rotla and FQM-151A Pointer, yet the performance of these two UAVs is vastly different. 


\section{Parameters Adopted by Manufactures for Rotary Wing Mini UAVs}

Rotary wing Mini UAVs made a relatively late entry. That's primarily because fixed wing aerial platforms took the lead in the development of unmanned systems, primarily due to ease of manufacture and military considerations. Longer endurance, range and higher operating altitudes gave distinct advantage to the larger UAVs while the complexities of the control mechanism could have discouraged makers from venturing into the rotary wing aerial vehicles in the smaller segment. However, in the context of Mini $\mathrm{UAV}$, where in the requirement of endurance and range is relatively lesser, the rotary UAV is optimally suited. The advancement in electronics, computer technology and artificial intelligence resolved much of the issues related to the control mechanism. Consequently, the interests in the rotary wing UAV gained momentum and is growing.

While there are numerous advantages of rotary wing aircraft, two distinct advantages of rotary wing mini UAV which make it appealing are as under.

- Vertical Take-off and Landing (VTOL) capability which enables it to take off from almost anywhere.

- $\quad$ The ability to hover gives a significant advantage for aerial photography, hence useful for reconnaissance and surveillance. 
PS and Jeyan: Parameters for Classification of a Mini UAV.

Table 3 gives out the parameters of some of the rotary Mini UAVs.

\begin{tabular}{|c|c|c|c|c|c|c|c|}
\hline \multicolumn{8}{|c|}{ Table 3 - Rotary Wing Mini UAV Parameters } \\
\hline $\begin{array}{c}\mathrm{S} / \mathrm{N} \\
\mathrm{o}\end{array}$ & Manufacturer & & $\begin{array}{c}\text { Rotor } \\
\text { Dia } \\
(\mathrm{m})\end{array}$ & $\begin{array}{c}\text { Max } \\
\text { Range } \\
(\mathrm{Km})\end{array}$ & $\begin{array}{l}\text { Altitude } \\
\text { (m) }\end{array}$ & Endurance & $\begin{array}{c}\text { MTOW } \\
(\mathrm{Kg})\end{array}$ \\
\hline 1 & $\begin{array}{l}\text { Yamaha Motor } \\
\text { Company }\end{array}$ & $\begin{array}{l}\text { Yamaha } \\
\text { RMAX Type } \\
\text { II }\end{array}$ & 3.1 & 0.15 & 2800 & $60 \mathrm{~min}$ & 94 \\
\hline 2 & Asturum Avia & $\begin{array}{l}\text { GSV-37 } \\
\text { Breeze }\end{array}$ & 2.2 & 0.15 & 1000 & $90 \min$ & 12 \\
\hline 3 & $\begin{array}{l}\text { Bertin } \\
\text { Technologies' }\end{array}$ & HoverEye & 2.1 & 35 & 3000 & $60 \mathrm{~min}$ & 18 \\
\hline 4 & Survey Copter & Copter 4 & 2.2 & 10 & 2500 & $150 \mathrm{~min}$ & 30 \\
\hline 5 & FT Sistemas & FT-100 FH & 2.5 & 40 & 1524 & $2.5 \mathrm{hr}$ & NA \\
\hline 6 & Scion UAS & $\begin{array}{l}\text { SA-200 } \\
\text { Weasel }\end{array}$ & 2.07 & 12 & 3050 & $2.5 \mathrm{hr}$ & 54 \\
\hline 7 & High Eye. & HEF 30 & 1.8 & NA & 3000 & $3.5 \mathrm{hrs}$ & 21 \\
\hline 8 & $\begin{array}{l}\text { UMS Aero } \\
\text { Group }\end{array}$ & Skeldar v-200 & 4.6 & $15-50$ & NA & $5 \mathrm{hrs}$ & 235 \\
\hline 9 & Swiss Drones & SDO 50V2 & 2.8 & 90 & 3000 & NA & 86 \\
\hline 10 & Swiss UAV & KOAX X-240 & 2.4 & NA & NA & $90 \mathrm{Min}$ & 45 \\
\hline 11 & $\begin{array}{l}\text { Delft } \\
\text { Dynamics }\end{array}$ & RH2 STERN & 1.8 & NA & 1000 & $90 \min$ & 15 \\
\hline 12 & $\begin{array}{l}\text { Sikorsky } \\
\text { Aircraft }\end{array}$ & Cypher & 1.22 & 18 & 2438 & $120 \mathrm{~min}$ & 120 \\
\hline 13 & FT Sistemas & FT-200 FH & 2.8 & NA & 3,658 & $12 \mathrm{hr}$ & 80 \\
\hline 14 & $\begin{array}{l}\text { AeroVironmen } \\
\mathrm{t}\end{array}$ & VAPOR 55 & 2.29 & 8 & 3657 & 1 & 24.9 \\
\hline 15 & $\begin{array}{l}\text { KB INDELA } \\
\text { Ltd }\end{array}$ & $\begin{array}{l}\text { INDELA- } \\
\text { I.N.SKY GCS }\end{array}$ & 3.1 & 100 & 1500 & 5 & 140 \\
\hline 16 & UAVOS & UVH 25EL & 2.6 & 67 & 3500 & 1.5 & 25 \\
\hline 17 & UAVOS & UVH 170 & 2.6 & 350 & 2500 & 5 & 45 \\
\hline 18 & Schiebel & $\begin{array}{l}\text { CAMCOPTER } \\
\text { S-100 }\end{array}$ & 3.4 & 200 & 5486 & 10 & 200 \\
\hline 19 & $\begin{array}{l}\text { Ukrspec } \\
\text { Systems }\end{array}$ & $\begin{array}{l}\text { PD-1 FW } \\
\text { VTOL } \\
\end{array}$ & 4.7 & 100 & 2500 & 12 & 45 \\
\hline 20 & $\begin{array}{l}\text { AeroVironmen } \\
\mathrm{t}\end{array}$ & $\begin{array}{l}\text { Quantix Recon } \\
\text { (VTOL) }\end{array}$ & 1 & 2 & 2826 & $45 \min$ & 2.3 \\
\hline 21 & Therod Sys & $\begin{array}{l}\text { EOS C UAS } \\
\text { (VTOL) }\end{array}$ & 4.6 & 50 & 2000 & 2 & 13 \\
\hline 22 & $\begin{array}{l}\text { Blue Bird } \\
\text { Aero System }\end{array}$ & $\begin{array}{l}\text { WanderB } \\
\text { VTOL } \\
\text { (VTOL) E M }\end{array}$ & 3.1 & 50 & 6705 & 2.5 & 13 \\
\hline 23 & ZALA Aero & $\begin{array}{l}\text { ZALA 421- } \\
16 \mathrm{EV} . \\
\text { (VTOL) }\end{array}$ & 2.8 & 100 & 2000 & 2 & 10.5 \\
\hline 24 & $\begin{array}{l}\text { Israel } \\
\text { Aerospace } \\
\text { Industries }\end{array}$ & Panther VTOL & 8.0 & 75 & 3048 & $6 \mathrm{hrs}$ & 63.5 \\
\hline
\end{tabular}


The Yamaha RMAX was amongst the first rotary wing UAV, which was developed in 1987. Since then, many players joined the fray. Wide variance of each of the parameters is amply evident. Compared to the fixed wing, endurance is one factor where rotary wing Mini UAV is much lower. Skeldar v-200 has a relatively lower endurance of 5 hours but it weighs $235 \mathrm{~kg}$ which may not suit the expected requirement of a Mini UAV. Range in most cases exceeds $10 \mathrm{Km}$ and would meet the desired tactical requirements. Operating altitude in the range of $3000 \mathrm{~m}$ will facilitate flexibility of employment in varied terrain. Most parameters of HEF 30 would meet the requirement at sub tactical level. Analysis of the parameters leads to similar conclusions as that of the fixed wing UAV.

\section{Discussion and Analysis}

The inconsistencies in theoretical references, with respect to the categorisation of Mini UAVs spill over to the manufacturing domain as well. As evident from various studies and the data of manufacturers, there is a lack of unanimity in defining the specifications and consequently there are divergent views regarding Mini UAVs. It is therefore apparent that both the classification and the categorisation of Mini UAV are not consistent. The graphs are based on the data from Tables 2 and 3.

\section{Range}

The contradictions and inconsistencies in the interrelationship of the range for Mini UAVs are depicted in Figure 3. Lack of correlation between various parameters is clearly evident from the figure below. The average range of $60.13 \mathrm{Km}$ provides a misleading conclusion since the dispersion in the ranges considered by the manufactures is noticeably high.

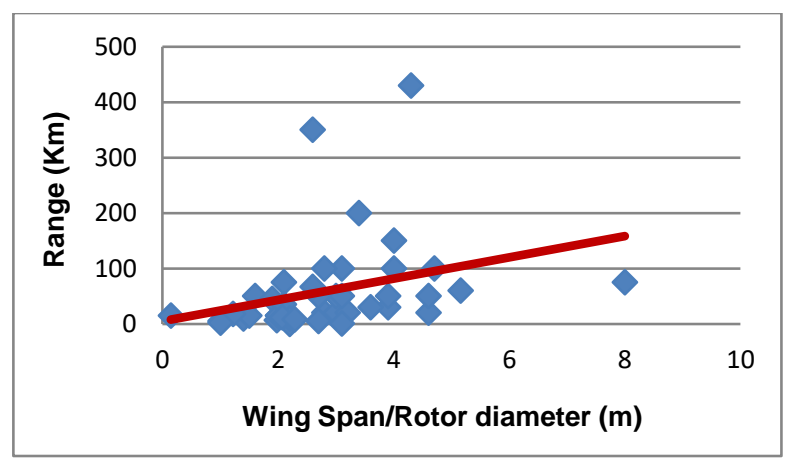

Figure 3. Range spread of Mini UAVs.

After excluding the outlier data by restricting the ranges between 5 and $100 \mathrm{~km}$, the average range is 40.14 hours. 


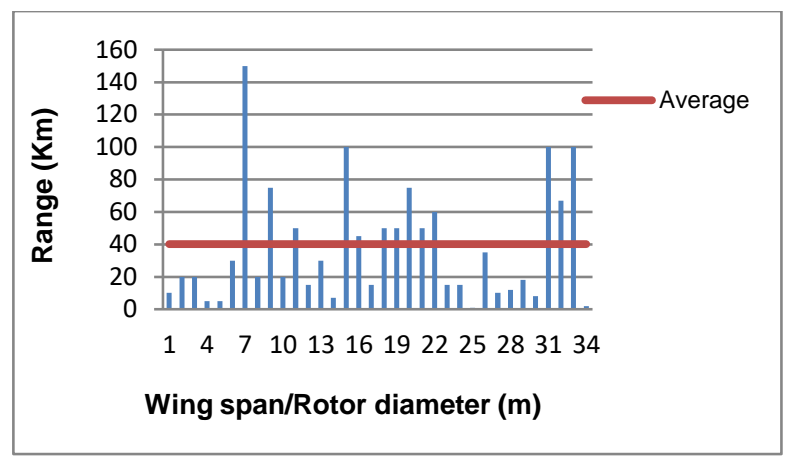

Figure 4. Average range of Mini UAVs.

As seen from Figure 4, this average may not be a true representation of the range of Mini UAVs. While considering the range spread, as seen in Figure 5, bulk of the UAVs have range lesser than $20 \mathrm{~km}$, while 55 percent has ranges within $40 \mathrm{Km}$. Considering all of the above, a range of 30-40 kilometers can be considered as working parameter.

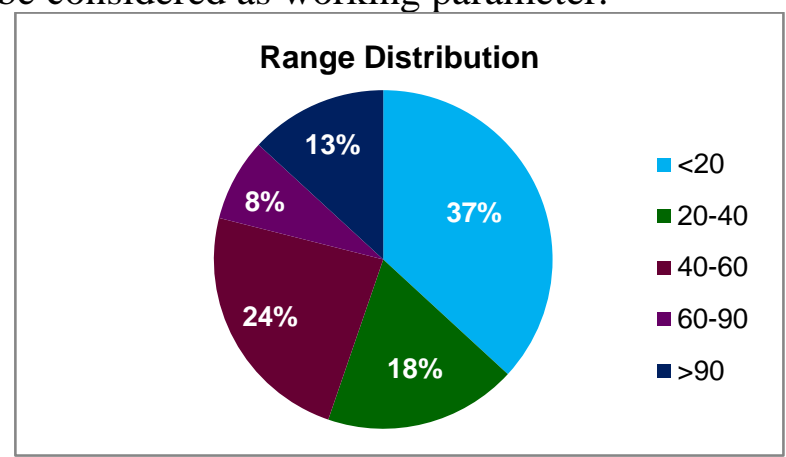

Figure 5. Range distribution of Mini UAVs.

\section{Operating Altitude}

Figure 6 illustrates the contradictions and inconsistencies in the interrelationship of the operating altitudes in case of Mini UAVs. There appears to be no correlation between the size of the Mini UAV and the operating altitude, corroborating the contradictions in the parameters that define a Mini UAV. The operating altitude in case ALADIN UAV with a wing span of $0.146 \mathrm{~m}$ operating at 4500 AMSL, as specified by the manufacturer, defies the trend. 


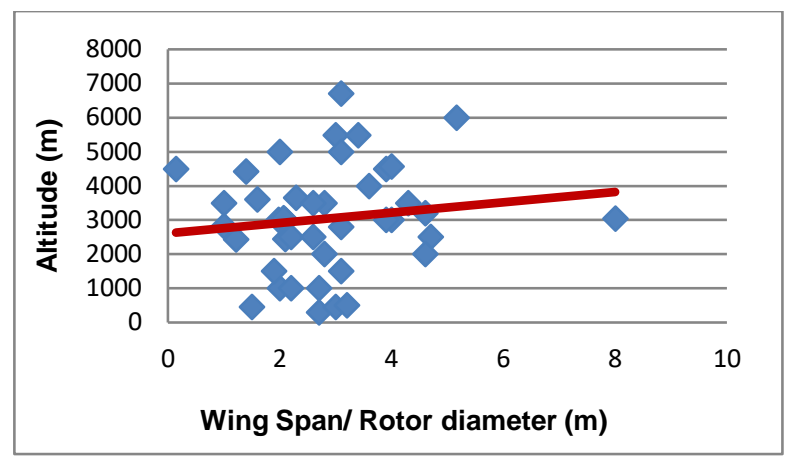

Figure 6. Altitude spread of Mini UAVs

The operating altitude varies from $300 \mathrm{~m}$ to $6705 \mathrm{~m}$ AMSL. Such wide variations make it difficult to set a benchmark operating altitude. The average operating altitude of the Mini UAVs under consideration is $3230 \mathrm{~m}$ AMSL. The value has been arrived at by ignoring the values below $1000 \mathrm{~m}$ and above $6000 \mathrm{~m}$.

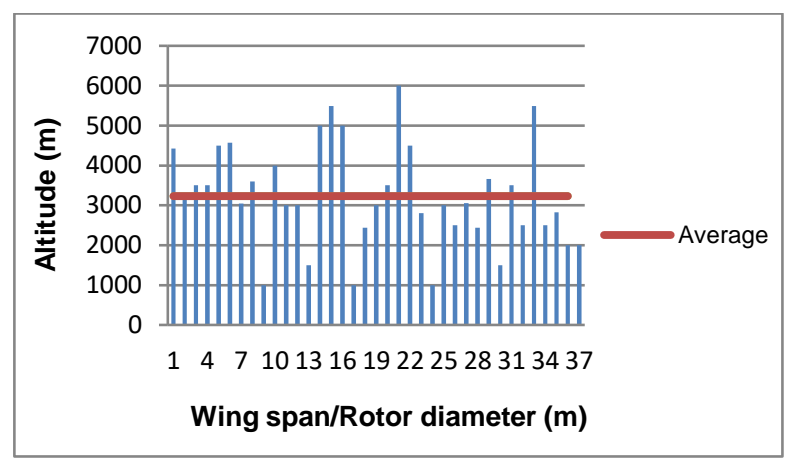

Figure 7. Average operating altitude of Mini UAVs.

As seen from Figure 8, more than $50 \%$ of the Mini UAV operates at altitudes between 2000 t0 $4000 \mathrm{~m}$ AMSL. Clubbed with the average value, it can be inferred that an operating altitude of around $3500 \mathrm{~m}$ AMSL can be a working parameter.

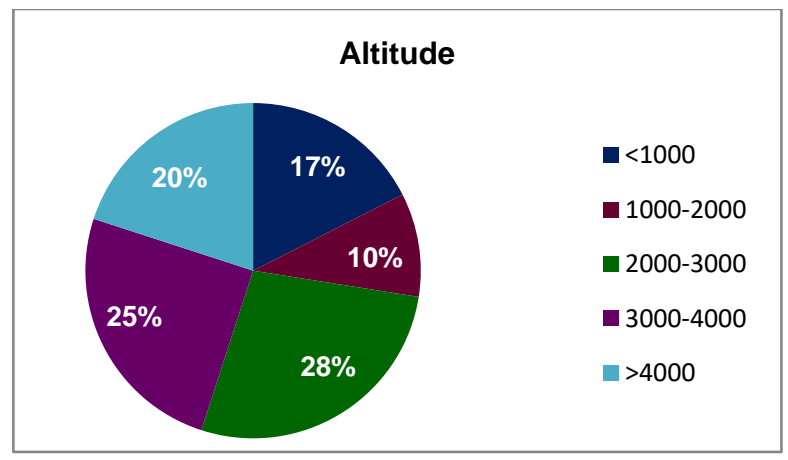

Figure 8. Operating altitude distribution of Mini UAVs. 


\section{Endurance}

Compared to range and operating altitude, dispersion in case of endurance is relatively less as evident from Figure 9, but aberrations do exist.

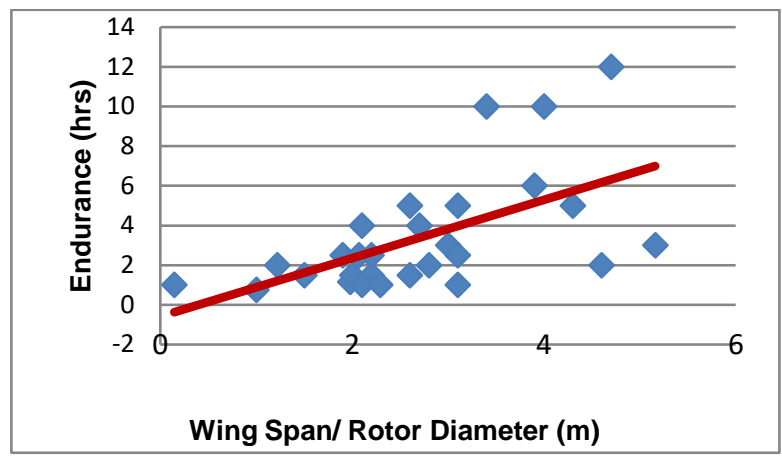

Figure 9. Endurance spread of Mini UAVs.

The VTOL profile Quantix Recon has only 45 minutes of endurance. At the other end of the spectrum, is Scan Eagle with 22 hours. Such a wide spectrum, yet again, highlights the inconsistencies in defining the operating parameters for Mini UAVs. The average endurance is 3 hours, after ignoring values below 1 hour and those above 10 hours. As seen from Figure10, barring a few spikes, the uniformity is more or less maintained.

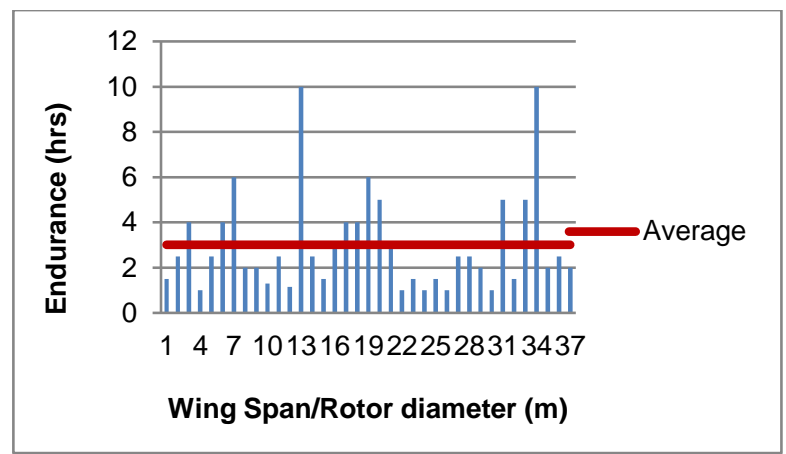

Figure 10. Average endurance of Mini UAVs.

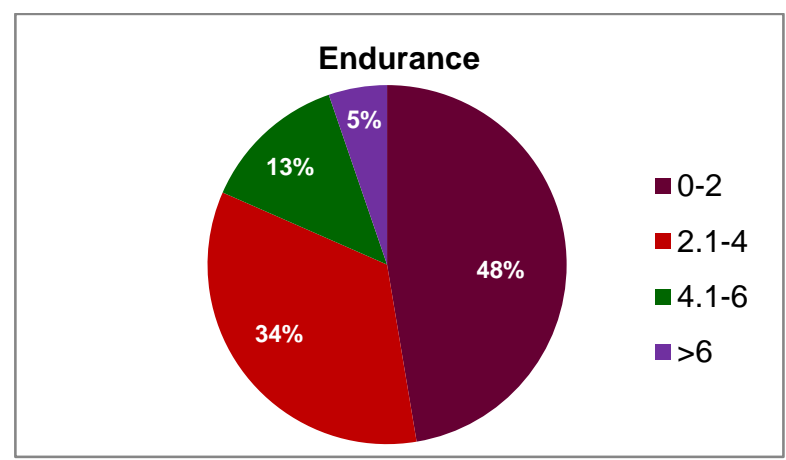

Figure 11. Endurance distribution of Mini UAVs. 
From Figure 11, it can be seen that $46 \%$ of the Mini UAVs has endurance between $2-4$ hours and $81 \%$ has between 2-6 hours. Therefore, as a working parameter, an endurance of 3-4 hours can be considered optimum. MTOW

The MTOW of few UAVs are significantly higher than the normal weight. However, as seen from Figure12, there are clusters of similar weights. Wasp at $1.4 \mathrm{Kg}$ is the lightest of the lot and CAMCOPTER S-100 with 200 $\mathrm{Kg}$ has the highest MTOW. The significantly wide variations in the MTOW make the assessment of a reasonable MTOW for Mini UAVs complex. Ignoring the outliers leaves very few data for analysis.

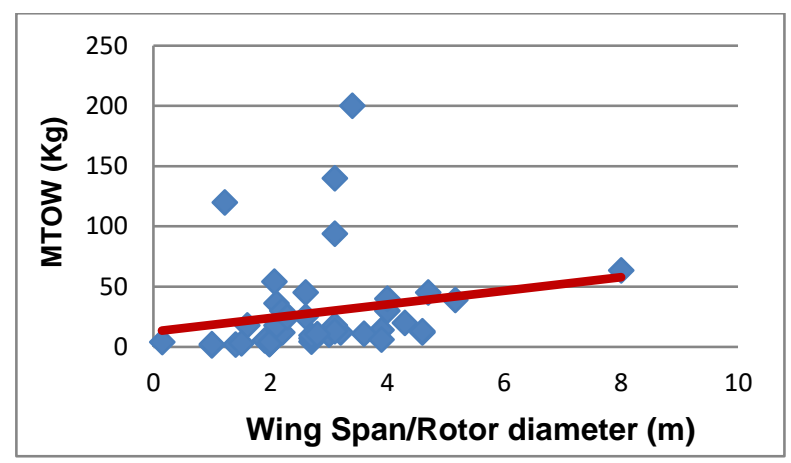

Figure 12. MTOW spread of Mini UAVs.

The MTOWs of the Mini UAVs, based on data from Table 2 and 3, is $28.93 \mathrm{Kg}$. As seen from Figure 13, this average can be a misleading figure because of the wide variation in the MTOW.

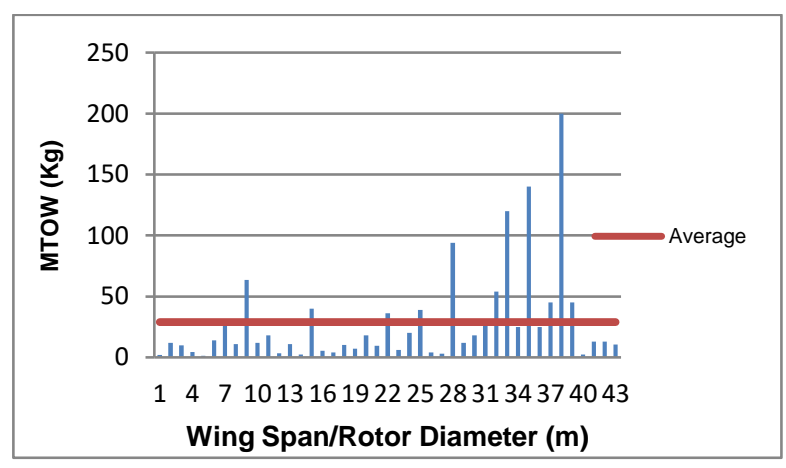

Figure 13. Average MTOW of Mini UAVs.

As seen from Figure 14, 33\% of Mini UAVs have MTOW in the category of $10-20 \mathrm{~kg}$. Twenty-nine percent (29\%) of Mini UAVs have MTOW less than this category, and 38\% have higher MTOW than the $10-20 \mathrm{~kg}$ category. Taking into account the wide variations in MTOW and the distribution of MTOW, it would be prudent to consider the average MTOW of $28.93 \mathrm{Kg}$. Therefore, $30 \mathrm{Kg}$ MTOW can be the working parameter. 


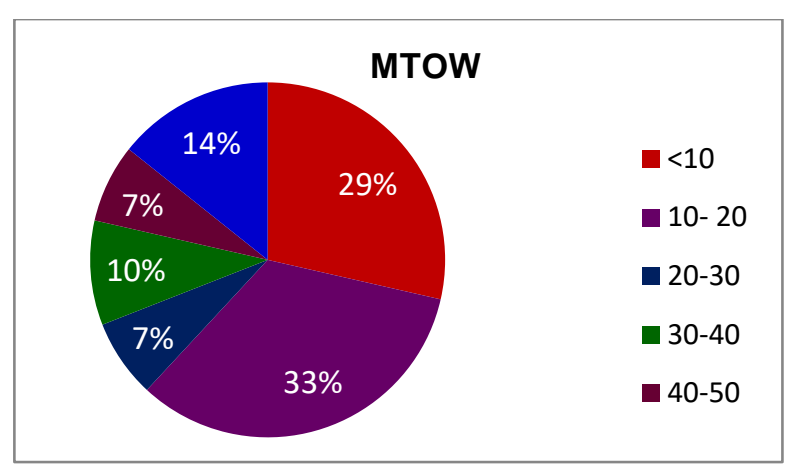

Figure 14. MTOW distribution of Mini UAVs

\section{Conclusions}

UAV of various sizes and shapes with a wide array of capabilities are being developed. While the distinction in the larger class of UAV is clear, the lines are blurred when it comes to the smaller ones. Small, Mini and Micro UAVs are often confused with each other. UAV of the same class can be utilised for a variety of applications, but the parameters which define the class has to be uniform. It is therefore imperative to have a common understanding of the parameters which would define a Mini UAV.

In most cases, the focus of the research has been on either the application or the scientific outcome with little considerations for the parameters. However, it is pertinent to mention that the applications of the UAV are based on the capabilities of the machine and this underscores the importance of the common comprehension of the parameters that categorise Mini UAV. Incorrect understanding of the definition of mini UAV can lead to misleading conclusions. Clearly defined specifications are particularly significant in case of military applications because of the tactical environment in which it has to operate.

With its proven capabilities, Mini UAV will continue to be used extensively, both in military and civilian applications, in the foreseeable future. There is a need for researchers to align themselves towards the industry needs and develop a common understanding of Mini UAVs. The paper has been an attempt to highlight the existing contradictions and lack of uniformity in defining a Mini UAV. A set of working parameters to categorise Mini UAVs have been arrived at, based on an array of analysis. These working parameters will require further examination. Researchers, students, manufacturers and users understanding must have a common understanding of a Mini UAV. Therefore, the need arrive at unambiguous parameters that specify a Mini UAV to bring all stakeholders to a common platform in the understanding of a Mini UAV cannot be overemphasised.

Conflicts of Interest: The authors declare no conflict of interest.

Corresponding Author: Dr J. V. Muruga Lal Jeyan, Department of Aerospace, School of Mechanical Engineering, Lovely Professional University, India. He can be contacted at : jvmlal@ymail.com 


\section{References}

Abdelwahid, B., Marija, S., Lamine, R., Zoran, R, \& Takieddine, M. (2019). UAV aerodynamic design involving genetic algorithm and artificial neural network for wing preliminary computation. Aerospace Science and Technology, 84, 464-483.

Anderson, K., \& Kevin, J. G. (2013). Lightweight unmanned aerial vehicles will revolutionize spatial ecology. Frontiers in Ecology and the Environment, 11(3), 138-146.

Aswini, N., Kumar, E.K., \& Uma, S.V. (2018). UAV and obstacle sensing techniques - a perspective. International Journal of Intelligent Unmanned Systems, 6, 32-46.

Austin, R. (2011). Unmanned aircraft systems: UAVs design, development and deployment. New York: John Wiley \& Sons.

Cai, G., Jorge, D., and Lakmal, S. (2014). A survey of small-scale unmanned aerial vehicles: Recent advances and future development trends. Unmanned Systems, 2(2), 175-199.

Gupta, S. G., Mangesh M. G., \& Jawandhiya, P. M. (2013). Review of unmanned aircraft system (UAS). International Journal of Advanced Research in Computer Engineering \& Technology (IJARCET), 2.4, 1652.

Hartanto, R., Arkeman, Y., Hermadi, I., Sjaf, S., \& Kleinke, M. (2019). Intelligent Unmanned Aerial Vehicle for Agriculture and Agroindustry. IOP Conf. Ser.: Earth Environ, 3-4.

Hassanalian, M. \& Abdelkefi, A. (2017). Classifications, applications, and design challenges of drones: A Review. Progress in Aerospace Sciences, 91, 99-131.

Hazim, S., Ahmad H., Sawalmeh, A. A., Zuochao, D., Eyad, A., Issa, K., Noor, S. O., Abdallah, K., \& Mohsen G. (2019). Unmanned aerial vehicles (UAVs): A Survey on Civil Applications and Key Research Challenges IEEE Access, 7,4-5.

Hsu, K., Murray, C., Cook, J., \& Feld, A. (2013) China's military unmanned aerial vehicle industry. U.S.-China Economic and Security Review Commission.

Jason, N. G., Ryan, M. W., Stephane, D. U., \& Yu, G. (2016). Flight-test evaluation of kinematic precise point positioning of small UAVs. International Journal of Aerospace Engineering.

John, D. B. (2010). Unmanned aerial systems: A historical perspective. Combat Studies Institute Press, 45, 2.

Jun, N., Lili, Y., Jingchao, Z., Weixing, C., Yan, Z., \& Xiuxiang, T. (2017) Development of an unmanned aerial vehicle-borne crop-growth monitoring system. Sensor, 17, 502-525.

Kadir, A.D., Halil, C., \& Nafiz, A. (2015). Unmanned aerial vehicle domain: Areas of research. Defence Science Journal, 65(4), 319-329.

Kamali, C., \& Shikha, J. (2016). Hardware in the loop simulation for a mini UAV. IFAC-Papers On Line, 49.1, 700-705. 
Laurence, R. N. (2004). Unmanned aviation: A brief history of unmanned aerial vehicles. American Institute of Aeronautics and Astronautics, 3, 12-13.

Lee, S., Tegoeh, T., \& Seung, K.M. (2015). Flexible membrane wing warping using tendon-sheath mechanism. Control and Automation (MED), 2015 23th Mediterranean Conference.

Louisa, B. H. (2015). Overview of military drones used by the UK armed forces. House of commons briefings.

Marin, G., Bosko, P., \& Almin D. (2014). Comparison and analysis of software solutions for creation of a digital terrain model using unmanned aerial vehicles. 14th International Multidisciplinary Scientific Geo Conference SGEM 3,4.

Maziar, A., Shane, A., Matthew M., Matthieu N., \& Tong Z. (2013). Classification of unmanned aerial vehicles. E3S Web of Conferences.

Quigley, M., Griffiths, S., Beard, R. W., Goodrich, M. A., \& Eldredge, A. (2005). Target acquisition, localization, and surveillance using a fixedwing mini-UAV and gimballed camera. International Conference on Robotics and Automation.

Rawat, K. S., \& Lawrence, E.E. (2014). A mini-UAV VTOL platform for surveying applications. IAES International Journal of Robotics and Automation, 3.4, 259.

US Office of the Secretary of Defense. (2005). Roadmap, unmanned aircraft systems (UAS) 2005-2030.

US Office of the Secretary of Defense, (2013). Roadmap, unmanned systems integrated roadmap 2013-2038.

Villa, T. F., Gonzalez, F., Miljievic, B., Ristovski, Z. D., \& Morawsk, L. (2016). An overview of small unmanned aerial vehicles for air quality measurements: Present applications and future prospectives. Sensors, 4.

Wang, L., Wang-ping, Z., \& Shi-lin, Z. (2013). Application of mini-UAV in emergency rescue of major accidents of hazardous chemicals. International Conference on Remote Sensing, Environment and Transportation Engineering, Atlantis Press.

Weed, S. C. (2002). The quality of quantity: Mini-UAVS as an alternative UAV acquisition strategy at the army brigade level. Army Command and General Staff Coll Fort Leavenworth KS School of Advanced Military Studies.

Weibel, R. E., \& Hansman, R. J. (2014). Safety considerations for operation of different classes of UAVs in the NAS. AIAA 4th Aviation Technology, Integration and Operations Forum. 